\title{
Corporal punishment and children's externalizing problems: A cross-sectional study of Tanzanian primary school aged children ${ }^{\text {茨 }}$
}

\author{
Tobias Hecker ${ }^{\mathrm{a}, \mathrm{b}, *}$, Katharin Hermenau ${ }^{\mathrm{a}, \mathrm{b}}$, Dorothea Isele ${ }^{\mathrm{a}, \mathrm{b}}$, Thomas Elbert ${ }^{\mathrm{a}, \mathrm{b}}$ \\ a Department of Psychology, University of Konstanz, 78567 Konstanz, Germany \\ b vivo international, Germany ${ }^{1}$
}

\section{Keywords:}

Corporal punishment

Externalizing problems

Aggressive behavior

Children

Sub-Saharan Africa

Tanzania

\begin{abstract}
A B S T R A C T
The adverse effect of harsh corporal punishment on mental health and psychosocial functioning in children has been repeatedly suggested by studies in industrialized countries. Nevertheless, corporal punishment has remained common practice not only in many homes, but is also regularly practiced in schools, particularly in low-income countries, as a measure to maintain discipline. Proponents of corporal punishment have argued that the differences in culture and industrial development might also be reflected in a positive relationship between the use of corporal punishment and improving behavioral problems in low-income nations. In the present study we assessed the occurrence of corporal punishment at home and in school in Tanzanian primary school students. We also examined the association between corporal punishment and externalizing problems. The 409 children (52\% boys) from grade 2 to 7 had a mean age of $10.49(S D=1.89)$ years. Nearly all children had experienced corporal punishment at some point during their lifetime both in family and school contexts. Half of the respondents reported having experienced corporal punishment within the last year from a family member. A multiple sequential regression analysis revealed that corporal punishment by parents or by caregivers was positively related to children's externalizing problems. The present study provides evidence that Tanzanian children of primary school age are frequently exposed to extreme levels of corporal punishment, with detrimental consequences for externalizing behavior. Our findings emphasize the need to inform parents, teachers and governmental organizations, especially in lowincome countries, about the adverse consequences of using corporal punishment be it at home or at school.
\end{abstract}

\section{Background}

Prevalence of corporal punishment in Tanzania and other low-income countries

The prevalence and effects of corporal punishment have been controversial topics for decades (Gámez-Guadix, Straus, Carrobles, Muñoz-Rivas, \& Almendros, 2010; Gershoff, 2002, 2010, 2013; Straus, 2001). Corporal punishment is commonly

\footnotetext{
t3 This research was supported by the Deutsche Forschungsgemeinschaft (DFG) and by the NGO vivo international.

* Corresponding author at: Department of Psychology, University of Konstanz, Box 23/25, 78457 Konstanz, Germany.

1 www.vivo.org.
} 
defined as 'the use of physical force with the intention of causing (bodily) pain, but not necessarily injury, for purposes of correction or control of the child's behavior' (Straus, 2010).

Research conducted in multiple countries has indicated that corporal punishment by parents is both more prevalent and more severe than is generally realized (Straus, 2010). In a study encompassing 32 countries on six continents, the rates of corporal punishment ranged from less than $20 \%$ in Sweden and the Netherlands to almost $75 \%$ in China. Research has shown the extensive use of corporal punishment in schools in resource-poor countries (Anderson \& Payne, 1994). For example in a UNICEF report on the use of corporal punishment against children in 35 middle- and low-income countries, six of the 10 countries in which corporal punishment was found to be very common are in Sub-Saharan Africa (UNICEF, 2010). In these countries more than $80 \%$ of the children reported frequent use of corporal punishment at home. In a study conducted in Nigeria, Ani and Grantham-McGregor (1998) described high levels of corporal punishment both at home and in school.

In Tanzania corporal punishment is still lawful not only at home but also at school. Although the law prohibits torture or other cruel or inhuman punishment, it allows corporal punishment as a means for justifiable correction. While only headteachers used to be allowed to punish corporally in Tanzanian schools, corporal punishment has just recently been reintroduced as a corrective measure usable by all teachers (Global Initiative to End All Corporal Punishment of Children, 2012; Tanzania Daily News, 2013). Therefore, it is not surprising that only $28 \%$ of secondary school students strongly disagreed that they were spanked or hit often before the age of 12 (Straus, 2010). In a study conducted at secondary schools in Tanzania, $40 \%$ of the teachers reported the frequent use of corporal punishment, defined as more than ten times a week. Interviews with teachers and students confirmed that caning (i.e. being beaten with a stick) was the most frequently used method of corporal punishment in schools (Feinstein \& Mwahombela, 2010). In 2009, a national survey concerning violence against children with a representative sample of more than 3700 youths between the ages of 13 and 24 found that almost threequarters of both girls and boys had experienced physical violence by a relative or an authority figure prior to the age of 18 (UNICEF, 2011). The vast majority of this corporal punishment consisted of being punched, whipped, or kicked. More than half of girls and boys aged 13-17 years reported that they had experienced physical violence by either a relative or authority figure during the past year. However, while much of the research has focused on the adolescent years little is known about the occurrence of corporal punishment at home for children of primary school age.

Proponents of corporal punishment have argued that the differences in culture and industrial development might be reflected in a positive relationship between the use of corporal punishment and improving behavioral problems in lowincome nations. For example, Lansford (2010) argues that parents and children in different cultures may interpret corporal punishment as either an appropriate and effective discipline strategy or not, depending on the normativeness of corporal punishment within their group. She states that although corporal punishment is generally related to more behavior problems regardless of cultural group, this association is weaker in countries in which corporal punishment is the norm. Yet cultures in which corporal punishment is the norm also have higher levels of societal violence (Lansford, Malone, Dodge, \& DeaterDeckard, 2010). Ellison and Bradshaw (2009) even claim that within cultural communities in which this practice is common and normative, its effects are less harmful. Vittrup and Holden (2010), however, have shown that children with high levels of exposure to corporal punishment were not likely to regard it as an effective disciplinary technique. Hence, they argue that the more prevalent the practice of corporal punishment is, the less likely it is that children perceive it as a fair and effective way to punish misbehavior. It may be perceived as too punitive if it occurs too often, and children who have many friends and siblings who experience corporal punishment may be exposed more to the negative comments about it from those friends and siblings (Vittrup \& Holden, 2010).

Furthermore, frequent use of corporal punishment in Tanzania and other countries may also be reinforced by the belief of many parents that their children intentionally misbehave and need to learn to respect the parent's authority to avoid long-term behavior problems (Burchinal, Skinner, \& Reznick, 2010) as well as by conservative religious and sociopolitical beliefs (Ellison \& Bradshaw, 2009).

Externalizing problems in low-income countries

Most studies on externalizing problems have been conducted in Western samples. However, one cross-cultural systematical review including different studies from Pakistan, Israel, Japan, and the United States concluded that many dimensions of aggressive behavior are universal. However, it also revealed some cultural distinctiveness, the most common type of aggressive behavior for example, as well as the meaning and the justification for the use of aggressive behavior (Severance et al., 2013). Savina, Coulacoglou, Sanyal, and Zhang (2011) suggested that children's externalizing and internalizing problems also have some specific cultural features. Findings from DR Congo, Ethopia and Nigeria showed that externalizing problems such as conduct disorder, antisocial disorder and hyperactivity are also a common phenomenon in Sub-Saharan Africa (Adelekan, Ndom, Ekpo, \& Oluboka, 1999; Ashenafi, Kebede, Desta, \& Alem, 2001; Kashala, Elgen, Sommerfelt, \& Tylleskar, 2005). In a representative sample from Ethopia using parent reports of 1477 children, Ashenafi et al. (2001) reported a prevalence rate of attention deficit hyperactivity disorder of $1.5 \%$ and of conduct disorder of $0.7 \%$. Adelekan et al. (1999) indicated a prevalence rate of antisocial disorders of $8 \%$ in a representative sample from Nigeria consisting of 846 parent reports. Kashala et al. (2005) compared their findings in a study with a representative sample in DR Congo using the teacher report version of the Strength and Difficulties Questionnaire (Goodman, Meltzer, \& Bailey, 1998) with prior findings from Great Britain. They found that the mean scores of the conduct problems subscale and the hyperactivity subscale were significantly higher than the British mean scores of a comparable sample. Hence, Cortina, Sodha, Fazel, and Ramchandani (2012) concluded that 
internalizing and externalizing mental problems are common in children in low and middle income countries such as some of those in Sub-Saharan Africa, and range overall from $12 \%$ to $29 \%$.

\section{Corporal punishment and its relation to externalizing problems}

Most available research indicated that there are few, if any, positive developmental outcomes associated with corporal punishment. In fact, detrimental effects of corporal punishment on the quality of the child-parent relationship, the children's mental health, and on children's externalizing behavior problems have been demonstrated repeatedly in a number of studies in populations mainly from Western countries (e.g. Gershoff, 2002, 2010, 2013). For example in addition to physical injury, corporal punishment and family violence are associated with a number of emotional and behavioral problems that begin in childhood but may last through adolescence and adulthood. Adverse effects include aggressive or delinquent behavior, conduct disorder, substance abuse, post-traumatic stress disorder, anxiety, depression, reduced self-esteem, and suicidal behavior (Catani, Jacob, Schauer, Kohila, \& Neuner, 2008; Hermenau et al., 2011; Hermenau, Hecker, Elbert, \& Ruf-Leuschner, in press; Repetti, Taylor, \& Seeman, 2002).

Of these links, the strongest has been shown to exist between corporal punishment and externalizing behavior problems, especially aggressive behavior (Gershoff, 2002, 2010, 2013; Straus \& Kantor, 1994). For example, Strassberg, Dodge, Pettit, and Bates (1994) found in a study with 273 kindergarten children and their parents that children whose parents reported that they have spanked their children in the last year showed higher levels of aggressive behavior toward their kindergarten peers. Trained observers who were unaware how the children have been disciplined rated the children's behavior in the classroom. Consequently, the researchers concluded that, in spite of parents' goals, corporal punishment failed to promote prosocial development and was instead associated with higher rates of aggressiveness toward peers. Other studies were able to replicate these findings, confirming the relationship between family violence or corporal punishment and both reactive and proactive aggression as well as delinquent and antisocial behavior in children and adolescents (Connor, Steingard, Cunningham, \& Anderson, 2004; Fantuzo \& Mohr, 1999; Schilling, Aseltine, \& Gore, 2007).

A longitudinal study conducted by Mulvaney and Mebert (2007) revealed that early corporal punishment was associated with increased externalizing behavior problems both in toddlerhood (36 months) and in first grade. Berlin et al. (2009) reported similar results from a large longitudinal study with low-income white, African American and Mexican American toddlers. Concordantly, experiencing corporal punishment at age 10 predicted violent behavior and delinquency in adolescence (Weaver, Borkowski, \& Thomas, 2008).

A meta-analysis provided further evidence of the association between corporal punishment and numerous forms of undesirable behavior: Corporal punishment was associated with, among others, an increase in child aggression, child delinquent and antisocial behavior, and an increase of aggression, criminal and antisocial behavior in adulthood (Gershoff, 2002). Despite controlling for children's temperament and earlier levels of aggression, parental use of corporal punishment continued to significantly predict children's later aggression (Weiss, Dodge, Bates, \& Pettit, 1992). Although it may lead to immediate compliance, corporal punishment is associated with less long-term compliance and prosocial behavior (Gershoff, 2002, 2013).

Thus, most studies in high-income countries have consistently linked corporal punishment with current and future aggressive behavior. The very few studies in low-income countries so far point at similar relations: for example in a study conducted in Nigeria, Ani and Grantham-McGregor (1998) linked exposure to corporal punishment both at home and in school to aggressive behavior in children. Moreover, in a study with orphans and vulnerable children in Tanzania, Hermenau et al. (2011) reported a positive relation between exposure to violence and aggressive behavior displayed by the child. However, the link between exposure to corporal punishment and children's externalizing problems has not been systematically examined in Sub-Saharan Africa, where caregivers and teachers have argued that corporal punishment may have different effects than in the industrialized world due to its role as part of "African culture".

In the present study, we investigated the occurrence of corporal punishment in the home and at school using a sample of Tanzanian primary school students. Vittrup and Holden (2010) confirmed that young children are able to articulate their views about corporal punishment. Therefore, we think it is important to add their voices to the debate, since children are the major recipients of corporal punishment. The occurrence of corporal punishment at home or at school for children of primary school age has not been systematically examined in Tanzania. However, based on prior reports that have focused on the adolescent years (e.g. Feinstein \& Mwahombela, 2010; UNICEF, 2011) and our extensive work with teachers and caregiver who have argued that corporal punishment is part of "African culture", we expected that corporal punishment is common and even normative in Tanzania. Therefore, we hypothesized that (a) primary school students in Tanzania experience frequent and severe corporal punishment in their home and at school.

Furthermore, we examined the relationship between corporal punishment at home and children's externalizing problems. Prior research has shown such a relationship for high-income countries (e.g. Gershoff, 2002, 2010, 2013; Weaver et al., 2008). Proponents of corporal punishment have argued that the detrimental effects of corporal punishment are weaker in countries in which corporal punishment is the norm (Ellison \& Bradshaw, 2009; Lansford, 2010). However, studies using children's reports give first evidence that this might not be the case (Vittrup \& Holden, 2010). In line with this, we argue that frequent corporal punishment will affect the children's well being despite being normative in Tanzania. We thus predicted (b) that exposure to corporal punishment is positively related to children's externalizing problems after controlling for possible 
confounding influences, such as sex and age. Furthermore, we expected that corporal punishment failed to promote prosocial behavior. Therefore, we hypothesized (c) a negative correlation between corporal punishment and prosocial behavior.

\section{Methods}

\section{Participants}

The children participating in this study were enrolled at a private primary school in a town of approximately 100,000 inhabitants in southern Tanzania. We interviewed 409 children (52\% boys) from class 2 to class 7 with a mean age of 10.49 $(S D=1.89$, range: $6-15)$ years. The majority of the children lived together with their families. We asked the children to list all persons with whom they stayed together in one household. For example $67 \%(n=273)$ of the children reported living together in one household with their mother and 59\% $(n=242)$ with their father. Sixty-five children (16\%) lived in institutional care and 10 children $(2.4 \%)$ in foster families. In total, $89(22 \%)$ children reported that at least one parent had died.

\section{Procedure}

A team of five Tanzanian psychologists, five German psychologists, and two Tanzanian psychology students conducted structured interviews with the children. All interviews were conducted in Swahili. The project leaders (TH and KH) were present throughout the training and data collection phases. The interviewers were qualified in the use of interview skills, conducting interviews with children, and the concepts of mental disorders and aggression, including role-plays and interview observation. The interviewers received instruction for these skills during a two-week training session. They were also trained in the translation of the instruments from English to Swahili and the translation of the participants' responses from Swahili to English for the German psychologists. All instruments were translated in written form to Swahili by committee and were intensely discussed to guarantee a precise translation. A written, blind back-translation into English ensured valid and accurate translation. One of the authors speaks Swahili fluently $(\mathrm{TH})$ and thus could ensure valid translation as well as supervise the work of the Tanzanian staff. In addition, the project leaders supervised the research team throughout all stages of the study. Interview teams either consisted of one German and one Tanzanian or one or two Tanzanian staff members. The interview teams rotated their pairings continuously. The interviewers had standardized the form of assessment by conducting joint and double-rated interviews to achieve a high level of inter-rater reliability. In the total sample, 33 interviews were double-rated to assess and ensure high inter-rater reliability.

Our study was conducted in close cooperation with the school. Before data collection we sent a letter and a written informed consent form to all parents or caregivers of the children from class 2 to 7 explaining the purpose of the study. The letter clarified that the participation of the children would be entirely voluntary, no monetary compensation would be offered, and invited them to call or meet the project leaders in case of additional questions. Approximately $80 \%$ of the parents and caregivers signed the informed consent and sent it back. Only children with an informed consent signed by their caregivers were included in the study. Additionally, the children gave their informed consent orally. Every child was interviewed individually in a calm setting. Girls were interviewed by a female interviewer. To ensure safety of the children we assured them that the interview was completely confidential and that they were free to end the interview at any time. The interview took $1.5 \mathrm{~h}$ on average. The Tanzanian Commission for Science and Technology and the Ethical Review Board of the University of Konstanz approved the study. Following the study we convinced the school to hire a school psychologist to help the children suffering from psychological problems and to raise awareness in teachers, parents and caregivers about the detrimental effects of child maltreatment.

\section{Measures}

All instruments were applied as a structured interview. In this way, even young children could be interviewed using all instruments. The first part of the interview consisted of socio-demographic information, including age, grade and sex.

Corporal punishment was assessed with a checklist of four questions covering possible forms of corporal punishment by parents and caregivers (see Table 2). In the present sample the score for corporal punishment types ranges from 0 to 4 (see Table 1 for descriptive statistics and inter-correlations). Additionally, we asked two questions regarding exposure to and observation of corporal punishment by teachers at school. Cronbach's Alpha coefficient was .42 and the Cohen's Kappa coefficient measuring the inter-rater reliability was >.99 (.99-1). Cronbach's Alpha coefficient is highly dependant on the number and the homogeneity of the items. Considering the limited number of items in this scale and the broad range of different forms of corporal punishment, the size of the Cronbach's Alpha coefficient can be viewed as sufficient.

Current aggressive behavior was assessed with the Reactive-Proactive Questionnaire (RPQ; Raine et al., 2006). The questionnaire assesses how often the child has shown a specific aggressive behavior in the previous four weeks. Possible answer categories are never (0), sometimes (1) and often (2). Following Hermenau et al. (2011) one of the original 23 items was removed, as it was not appropriate for the conditions in Tanzania (Item 18: Made obscene phone calls for fun) and one item was slightly rephrased for a better understanding (Item 9: gang fight replaced with fight). This study used the current aggression score, which ranges from 0 to 44 (see Table 1 for descriptive statistic and inter-correlations). In the present sample the Cronbach's Alpha coefficient was .85 and the Cohen's Kappa coefficient was .99 (.94-1). 
Table 1

Descriptive statistics and inter-correlations of all relevant variables.

\begin{tabular}{|c|c|c|c|c|c|c|c|c|c|c|c|c|}
\hline & $n$ & $M$ & $S D$ & Range & 1 & 2 & 3 & 4 & 5 & 6 & 7 & 8 \\
\hline 1. Corporal punishment types & 409 & 2.29 & 1.07 & $0-4$ & 1 & & & & & & & \\
\hline 2. Current aggressive behavior & 408 & 8.53 & 5.74 & $0-31$ & $.33^{* * *}$ & 1 & & & & & & \\
\hline 3. Lifetime aggression types score & 396 & 3.62 & 2.75 & $0-12$ & $.35^{* * *}$ & $.56^{* * *}$ & 1 & & & & & \\
\hline 4. Conduct problems (SDQ) & 409 & 2.18 & 1.84 & $0-8$ & $.28^{* * *}$ & $.40^{* * *}$ & $.34^{* * *}$ & 1 & & & & \\
\hline 5. Hyperactivity score (SDQ) & 409 & 2.64 & 2.00 & $0-9$ & $.24^{* * *}$ & $.35^{* * *}$ & $.32^{* * *}$ & $.49^{* * *}$ & 1 & & & \\
\hline 6. Externalizing problems score & 396 & -0.03 & 2.35 & -5.3 to 9.2 & $.40^{* * *}$ & $.77^{* * *}$ & $.75^{* * *}$ & $.74^{* * *}$ & $.72^{* * * *}$ & 1 & & \\
\hline 7. Prosocial behavior score (SDQ) & 409 & 7.88 & 1.72 & $2-10$ & $-.11^{*}$ & $-.13^{* *}$ & $-.14^{* *}$ & $-.23^{* * *}$ & $-.27^{* * *}$ & $-.27^{* * *}$ & 1 & \\
\hline
\end{tabular}

Note: $M=$ mean, $S D=$ standard deviation.

${ }^{*} p \leq .05$.

${ }^{* *} p \leq .01$.

${ }^{* * *} \quad p \leq .001$

We assessed lifetime aggression and delinquent behavior with a checklist of 14 questions covering possible aggressive and delinquent actions during the child's life. Sample items include "Have you ever taken things from others against their will?", "Have you ever physically attacked another person (e.g. punched, beaten up, kicked or hit with an object)?" or "Have you ever injured another person dangerously?" In a manner similar to a trauma checklist we assessed the presence of different categories of aggression and delinquent behavior but not the number of occurrences. Therefore, the interviewer rated the child's report as never happened in life (0) or happened at least one time (1). This checklist has been successfully used in a sample of Burundian street children (Crombach \& Elbert, 2013). We calculated a sum score by totaling up all of the question responses. The score of lifetime aggression types ranged from 0 to 14 (see Table 1 for descriptive statistic and inter-correlations). In the present sample the Cronbach's Alpha coefficient was .77 and the Cohen's Kappa coefficient was $>99(.94-1)$.

The self-evaluation of internalizing and externalizing problems was assessed with the Strengths and Difficulties Questionnaire (SDQ; Goodman et al., 1998). The SDQ comes with good psychometric properties and is utilized internationally (Goodman, Ford, Simmons, Gatward, \& Meltzer, 2000). We used the self-report version for children in the structured interview. It consists of 25 statements with corresponding response categories of not true (0), somewhat true (1) or certainly true (2). Each of the five subscales (conduct problems, hyperactivity, emotional symptoms, peer problems and prosocial behavior) consists of five items. The total difficulties score is generated by summing the scores of all items, except the items for prosocial behavior, and ranges from 0 to 40 . On average, the participants reported a SDQ total score of $M=10.08(S D=5.58$, range: $0-31$ ). In the present sample the Cronbach's Alpha coefficient of the total score was .67 and the Cohen's Kappa coefficient was .99 (.94-1). The heterogeneity of the total score, including two subscales of internalizing and two subscales of externalizing problems explains the moderate level of Cronbach's Alpha coefficient.

In the present study we focused on the two subscales measuring externalizing problems (i.e. conduct problems subscale and hyperactivity subscale) as well as the prosocial behavior scale (see Table 1 for descriptive statistic and inter-correlations). Each subscale ranges from 0 to 10 . A score of 4 on the conduct problem scale indicates an enhanced level of conduct problems and a score higher than 4 indicates an abnormal level. In total, 323 (79\%) showed a normal level of conduct problems, 36 (9\%) showed an enhanced level and 50 (12\%) showed an abnormal level of conduct problems. In the present sample the Cronbach's Alpha coefficient of the conduct problems scale was .54 and the Cohen's Kappa coefficient was .99 (.94-1). A score of 6 on the hyperactivity scale indicates an enhanced level of hyperactivity and a score higher than 6 indicates an abnormal level. In total, 373 (91\%) showed a normal level of hyperactivity, 21 (5\%) showed an enhanced level and 15 (4\%) showed an abnormal level of hyperactivity. In the present sample the Cronbach's Alpha coefficient of the hyperactivity scale was .51 and the Cohen's Kappa coefficient was .98 (.96-1). A score of 5 on the prosocial behavior scale indicates a lowered level of prosocial behavior and a score lower than 5 indicates an abnormal level. In total, 367 (89\%) showed a normal level of prosocial behavior, 27 (7\%) showed a lowered level and 15 (4\%) showed an abnormal level of prosocial behavior. In the present sample the Cronbach's Alpha coefficient of the conduct problems scale was .52 and the Cohen's Kappa coefficient was $>99$ (.99-1). The size of the Cronbach's Alpha coefficient depends on the number of items. Since all subscales consist of only five items the size of Cronbach's Alpha for the subscales is satisfactory. All in all, we found very similar patterns and results as Kashala et al. (2005) who used the teacher report version in an urban sample in DR Congo.

\section{Data analysis}

For logistical reasons, thirteen interviews could not be completed. This resulted in all thirteen cases missing data concerning lifetime aggression and, in one case, missing data concerning current aggressive behavior. These data sets were excluded from all analyses that included these measures.

To test the relationship between corporal punishment and different measures of externalizing problems (e.g. current and lifetime aggressive behavior, conduct problems and hyperactivity) as well as prosocial behavior we used Pearson's correlation coefficient. Furthermore, we wanted to examine the impact of corporal punishment on externalizing problems in general. Therefore, we computed a global externalizing problems score. As all scores measuring externalizing problems 
Occurrence of corporal punishment during the children's lifetime and within the last 12 months for boys $(n=214)$ and girls ( $n=195$ ).

\begin{tabular}{|c|c|c|c|c|c|c|}
\hline & \multicolumn{3}{|c|}{ Last year } & \multicolumn{3}{|c|}{ Lifetime } \\
\hline & $\begin{array}{l}\text { Boys } \\
\%(n)\end{array}$ & $\begin{array}{l}\text { Girls } \\
\%(n)\end{array}$ & $C h i^{2}$ & $\begin{array}{l}\text { Boys } \\
\%(n)\end{array}$ & $\begin{array}{l}\text { Girls } \\
\%(n)\end{array}$ & $C h i^{2}$ \\
\hline $\begin{array}{l}\text { (1) Has your parent/caregiver intentionally } \\
\text { pinched, slapped, punched or kicked you? }\end{array}$ & $27(58)$ & $27(53)$ & $<0.01$ & 69 (148) & $63(122)$ & 1.98 \\
\hline $\begin{array}{l}\text { (2) Has your parent/caregiver spanked you with } \\
\text { the palm of his/her hand on your buttocks, arms } \\
\text { or legs? }\end{array}$ & $23(49)$ & $24(48)$ & 0.08 & 55 (117) & 59 (114) & 0.60 \\
\hline $\begin{array}{l}\text { (3) Has your parent/caregiver spanked you with an } \\
\text { object such as a strap, belt, stick, tube, broom, } \\
\text { wooden spoon, etc.? }\end{array}$ & $36(76)$ & $37(72)$ & 0.09 & 83 (178) & 81 (158) & 0.32 \\
\hline $\begin{array}{l}\text { (4) Has any parent/caregiver hit you so hard that } \\
\text { you were injured? }\end{array}$ & $7(14)$ & $3(6)$ & 2.63 & $26(56)$ & $22(43)$ & 0.94 \\
\hline $\begin{array}{l}\text { (5) Has your teacher intentionally pinched, } \\
\text { slapped, punched or spanked (including with an } \\
\text { object, e.g. a stick) you? }\end{array}$ & - & - & - & 98 (210) & 91 (178) & $9.83^{* *}$ \\
\hline $\begin{array}{l}\text { (6) Have you witnessed that your teacher } \\
\text { intentionally pinched, slapped, punched or } \\
\text { spanked (including with an object, e.g. a stick) } \\
\text { another student? }\end{array}$ & - & - & - & 98 (209) & 99 (192) & 0.34 \\
\hline
\end{tabular}

Note: $C h i^{2}:$ Pearson's chi-squared test statistics.

${ }^{* *} p \leq .01$.

are significantly correlated (see Table 1), we z-standardized the current aggression score (RPQ), the lifetime aggression score, the hyperactivity score (SDQ) and the conduct problem score (SDQ) and calculated an externalizing problems score by summing up these four z-scores (see Table 1 for descriptive statistics and inter-correlations). To test the relationship between corporal punishment and externalizing problems we conducted a multiple sequential regression analysis. First, we included only the potentially confounding variables sex (female: 0 ; male: 1 ) and age as predictors. After controlling for these influences, we added 'corporal punishment types' to the model. The regression model fulfilled all necessary quality criteria for linear regression analyses. The residuals did not deviate significantly from normality (Kolmogorow $-S m i r n o v-Z=0.99$, $p=.285$ ), linearity, or homoscedasticity. Following Stevens (2002), we defined values that deviate more than 3 standard deviations from the mean as outliers. That way we identified two univariate and eight multivariate (Cook's Distance) outliers. Consequently, all outliers were excluded resulting in a sample size of $n=386$. The maximum Variance Inflation Factor did not exceed 1.05. As a result, we did not need to take multicollinearity into account. All analyses used a two-tailed $\alpha=.05$. Our metric for a small effect size was $f^{2} \geq .02$, for a medium effect $f^{2} \geq .15$, and for a large effect $f^{2} \geq .35$ (Cohen, 1992 ). Data was analyzed with IBM SPSS Statistics Version 21 for Mac.

\section{Results}

\section{Occurrence of corporal punishment}

Accounting for all forms of corporal punishment reviewed in the present study, $95 \%$ of the children reported that they have experienced at least one type of corporal punishment by their parents or caregivers during their lifetime (51\% within the previous 12 months). The majority of the children have been punished with objects like sticks or belts (82\%) or by being slapped, hit or pinched (66\%). Almost one quarter (24\%) has been hit so hard that he/she was injured. Additionally, about $95 \%$ reported having experienced corporal punishment at school and 98\% having witnessed corporal punishment used against other children at school. Boys reported that they have experienced corporal punishment by teachers at school significantly more often $(98 \%)$ than girls $\left(91 \%\right.$; $\left.C h i^{2}=9.83, p=.003\right)$. Table 2 displays the frequencies of all different types of corporal punishment during the children's lifetime and within the last 12 months separately for boys and girls.

\section{Corporal punishment and externalizing problems}

Corporal punishment correlated significantly positively with current and lifetime aggressive behavior, conduct problems and hyperactivity (see Table 1). Furthermore, corporal punishment was significantly negatively correlated with prosocial behavior (see Table 1).

The first regression model with sex and age as predictors explained $2 \%$ of the variance of the externalizing problems sore $\left(R^{2}=.02, F(2,383)=4.61, p=.011, f^{2}=.02\right)$. Adding the corporal punishment score as additional predictor improved the model significantly $\left(\Delta R^{2}=.16, F(1,382)=76.55, p<.001, f^{2}=.19\right)$. As shown in Table 3, 'corporal punishment types' were positively related to the externalizing problems score. The total regression model explained $18 \%$ of the variability of the externalizing problem score. 
Table 3

Results of regression analysis predicting the externalizing problems score.

\begin{tabular}{|c|c|c|c|c|}
\hline \multirow[t]{2}{*}{ Predictor variables } & \multicolumn{4}{|c|}{ Externalizing problems score } \\
\hline & $B$ & $S E$ of $B$ & $\beta$ & $T$ \\
\hline \multicolumn{5}{|l|}{ Step 1} \\
\hline Sex & 0.80 & 0.28 & .14 & $2.81^{* *}$ \\
\hline Age & -0.12 & 0.08 & -.08 & -1.63 \\
\hline \multicolumn{5}{|l|}{ Step 2} \\
\hline Sex & 0.60 & 0.26 & .11 & $2.31^{*}$ \\
\hline Corporal punishment types & 1.07 & 0.12 & .41 & $8.75^{* * *}$ \\
\hline
\end{tabular}

Note: $\operatorname{adj} R^{2}=.18, f^{2}=0.22, n=386, B$ : unstandardized regression weight, $S E$ : standard error, $\beta=$ standardized regression weight, $T$ : $t$-test statistics.

${ }^{*} p \leq .05$.

${ }^{* *} p \leq .01$

*** $p \leq .001$.

\section{Discussion}

In accordance with our hypothesis we found very high rates of exposure to corporal punishment in our sample. Almost all children reported having experienced at least one type of corporal punishment at home. In addition, more than half of the children indicated having experienced at least one type of corporal punishment by a parent or a caregiver in the past 12 months. The majority of the children (82\%) stated that they have been punished with sticks, belts or other objects, and almost one quarter of the entire sample has been punished so severely that they have been injured as a result. In addition to the in-home findings, we also found high rates of corporal punishment by teachers in school. Our findings are in concordance with prior research concerning corporal punishment in Tanzania (Feinstein \& Mwahombela, 2010; UNICEF, 2011) and other countries (Straus, 2010; UNICEF, 2010). Using a systematic approach to completely assess grades 2 through 7 in one primary school, for the first time we provide evidence that high rates of corporal punishment at home and in school seem to be not only common for adolescents but also for primary school-aged children in Tanzania. We can thus conclude that exposure to corporal punishment is the norm rather than an exception for primary school aged children in Tanzania.

All types of externalizing problems (current and lifetime aggressive behavior, conduct problems and hyperactivity) correlated positively with corporal punishment, whereas prosocial behavior correlated negatively with corporal punishment. Even after controlling for the possible influences of sex and age, corporal punishment by parents or caregivers substantially predicted the children's externalizing problems. The more children had reported experiencing corporal punishment the higher were their rates of externalizing problems. Our findings were in concordance with prior reports from Sub-Saharan Africa (Ani \& Grantham-McGregor, 1998; Hermenau et al., 2011). Similar relations between corporal punishment or family violence and externalizing problems have been reported in other countries worldwide (Connor et al., 2004; Fantuzo \& Mohr, 1999; Schilling et al., 2007). Our results stand in contrast to the common assumptions made by many parents and caregivers as well as researchers (Ellison \& Bradshaw, 2009; Lansford, 2010) that corporal punishment promotes prosocial behavior. Instead, our findings suggest the opposite, with a robust positive association between any amount of corporal punishment and children's externalizing problems including aggressive behavior and a negative relationship between corporal punishment and children's prosocial behavior. These results match prior research with a focus on Western countries (Berlin et al., 2009; Gershoff, 2002; Strassberg et al., 1994).

Furthermore, our results contradict the common assumption made by proponents of corporal punishment that it does no or less harm in countries or cultural groups in which corporal punishment is the norm rather than the exception (e.g. Ellison \& Bradshaw, 2009; Lansford, 2010). In the present study the effect size of this association implies a marked influence. Considering that $95 \%$ of the children in our sample have experienced at least one type of corporal punishment, the effects on the level of externalizing problems of so many children may manifest into a considerable cause for concern at the societal level (Straus, 2001). That is even more troubling when one considers the cumulative effect of corporal punishment on a child's overall well-being, including increased aggression, and decreased mental health (Catani et al., 2008; Felitti et al., 1998; Gershoff, 2002; Straus, 2001). Longitudinal research suggests that exposure to corporal punishment during childhood predicts aggression and antisocial or delinquent behavior in adolescence and adulthood (Berlin et al., 2009; Dodge, Pettit, Bates, \& Valente, 1995; Mulvaney \& Mebert, 2007; Weaver et al., 2008). High rates of corporal punishment hold the risk that victimized children may grow into adolescents or adults with increased aggressive behavior, conduct problems, and other mental health issues. Thus, further longitudinal studies are needed to investigate the causal relationship between corporal punishment and externalizing problems such as aggressive behavior, particularly in countries and societies with high levels of corporal punishment. Bearing the extremely high rates of corporal punishment in this study in mind, the link between corporal punishment and externalizing problems has the potential to pose serious challenges to societies in which it is widely practiced, such as the society in Tanzania.

Our findings indicate that effective prevention of corporal punishment may be required to help prevent children from developing externalizing problems. Preventative measures could focus on positive parenting and non-violent caregiving strategies. The reasons for using corporal punishment provided to researchers seem to be the lack of non-violent caregiving 
skills, excessive demands, and helplessness (Burchinal et al., 2010; Hermenau et al., 2011). Therefore parents and teachers may profit from learning non-violent parenting and disciplinary skills (for a possible approach see Hermenau et al., 2011). With this aim in mind, future research should focus on developing and testing culturally appropriate prevention programs for corporal punishment addressing both families and schools.

There are several limitations of the study that should be noted: first, the cross-sectional study design does not allow for the establishment of causality. For instance, it may be argued that those who display more externalizing problems would have deserved and received greater punishment. This, however, seems unlikely since we assessed corporal punishment that had occurred during the entire lifespan of the children and it correlates with the current externalizing problems (see Table 1). If children's aggressive behavior would have been penalized in their past and if the use of corporal punishment had been successful, children reporting having experienced high levels of corporal punishment during the course of their entire lifetime should not report current aggressive behavior and other externalizing problems. Second, we studied only one primary school in Tanzania and although it included children from varied social backgrounds, general prevalence rates cannot be derived from the present data alone. However, results are consistent with previous findings and in line with observations the authors have made during the course of visits to a number of schools in rural Tanzania and elsewhere in East Africa. This study also did not focus on the details of corporal punishment carried out by teachers. While this study provides some insight, further research, particularly in public schools, is needed to investigate the association between corporal punishment by teachers and externalizing problems. Generally, the children talked very openly about their experiences and feelings. However, potential biases, such as social desirability, can never be completely ruled out for subjective reports.

\section{Conclusion}

The present study provides evidence for the first time that Tanzanian children of primary school age experience high rates of corporal punishment. Furthermore, the results revealed that corporal punishment is closely linked to children's externalizing problems.

The findings of the present study emphasize the need to inform caregivers, governmental organizations and the population at large, especially in low-income countries, about the adverse consequences associated with using corporal punishment both at home and at school. Further, our findings underscore the need to implement preventative measures against the use of corporal punishment both at home and at school, in resource-poor countries as well as in industrialized nations. Therefore, we advocate for developing and testing culturally appropriate prevention programs that effectively replace corporal punishment by forms of educational measures that do not harm the children. Through these efforts, reducing corporal punishment in their home and school environments combined with the fostering of positive parenting skills we would enable more children to grow up in a respectful and supportive atmosphere, thereby strengthening their development.

\section{Competing interests}

The authors declare that they have no competing interests.

\section{Acknowledgements}

We are grateful to all the children who participated in this study for their readiness to participate and willingness to discuss often intimate and painful subjects. We also wish to thank all of the teachers, the head teacher and the director of the school for their support while conducting this study. We are very grateful to our very motivated and reliable German and Tanzanian research team, including: Manswab Geho, Huruma Kipagile, Getrude Mkinga, Andrew Mtitu, Zephania Ngowi, Lulu Nziku, Astrid Pabst, Charlotte Salmen, and Leila Samson. Without their support this study would not have been possible. We also thank Justin Preston who critically reviewed the manuscript.

\section{References}

Adelekan, M., Ndom, R., Ekpo, M., \& Oluboka, O. (1999). Epidemiology of childhood behavioural disorders in Ilorin, Nigeria - Findings from parental reports. West African Journal of Medicine, 18(1), 29-48.

Anderson, S., \& Payne, M. (1994). Corporal punishment in elementary education: Views of Barbadian schoolchildren. Child Abuse E Neglect, 18(4), 377-386. http://dx.doi.org/10.1016/0145-2134(94)90040-X

Ani, C., \& Grantham-McGregor, S. (1998). Family and personal characteristics of aggressive Nigerian boys: Differences from and similarities with Western findings. Journal of Adolescent Health, 23(5), 311-317. http://dx.doi.org/10.1016/S1054-139X(98)00031-7

Ashenafi, Y., Kebede, D., Desta, M., \& Alem, A. (2001). Prevalence of mental and behavioural disorders in Ethiopian children. East African Medical Journal, 78(6), 308-311.

Berlin, L. J., Ispa, J. M., Fine, M. A., Malone, P. S., Brooks-Gunn, J., \& Brady-Smith, C. (2009). Correlates and consequences of spanking and verbal punishment for low-income White, African American, and Mexican American toddlers. Child Development, 80(5), 1403-1420. http://dx.doi.org/10.1111/j.1467-8624.2009.01341.x

Burchinal, M., Skinner, D., \& Reznick, J. S. (2010). European American and African American mothers' beliefs about parenting and disciplining infants: A mixed-method analysis. Parenting: Science and Practice, 10, 79-96. http://dx.doi.org/10.2080/15295190903212604

Catani, C., Jacob, N., Schauer, E., Kohila, M., \& Neuner, F. (2008). Family violence, war, and natural disasters: A study of the effect of extreme stress on children's mental health in Sri Lanka. BMC Psychiatry, 8, 33. http://dx.doi.org/10.1186/1471-244X-8-33

Cohen, J. (1992). A power primer. Psychological Bulletin, 112(1), 155-159. http://dx.doi.org/10.1037/0033-2909.112.1.155 
Connor, D. F., Steingard, R. J., Cunningham, J. A., \& Anderson, J. J. (2004). Proactive and reactive aggression in referred children and adolescents. American Journal of Orthopsychiatry, 74, 129-136. http://dx.doi.org/10.1037/0002-9432.74.2.129

Cortina, M. A., Sodha, A., Fazel, M., \& Ramchandani, P. G. (2012). Prevalence of child mental health problems in Sub-Saharan Africa. Archives of Pediatrics E Adolescent Medicine, 166(3), 276-281.

Crombach, A., \& Elbert, T. (2013). Building up resilience by dealing aggressively with insecurity - A study with children in Burundi. (submitted for publication).

Dodge, K. A., Pettit, G. S., Bates, J. E., \& Valente, E. (1995). Social information-processing patterns partially mediate the effect of early physical abuse on later conduct problems. Journal of Abnormal Psychology, 104(4), 632-643. http://dx.doi.org/10.1037/0021-843X.104.4.632

Ellison, C. G., \& Bradshaw, M. (2009). Religious beliefs, sociopolitical ideology, and attitudes toward corporal punishment. Journal of Family Issues, 30(3), 320-340. http://dx.doi.org/10.1177/0192513X08326331

Fantuzo, J., \& Mohr, W. (1999). Prevalence and effects of child exposure to domestic violence. The Future of Children, 9(3), 21-32. http://dx.doi.org/ $10.2307 / 1602779$

Feinstein, S., \& Mwahombela, L. (2010). Corporal punishment in Tanzania's schools. International Review of Education, 56, 399-410. http://dx.doi.org/ $10.1007 / \mathrm{s} 11159-010-9169-5$

Felitti, V. J., Anda, R. F., Nordenberg, D., Williamson, D. F., Spitz, A. M., Edwards, V., Koss, M. P., \& Marks, J. S. (1998). Relationship of childhood abuse and household dysfunction to many of the leading causes of death in adults. The Adverse Childhood Experiences (ACE) Study. American Journal of Preventive Medicine, 14(4), 245-258. http://dx.doi.org/10.1016/S0749-3797(98)00017-8

Gámez-Guadix, M., Straus, M. A., Carrobles, J. A., Muñoz-Rivas, M. J., \& Almendros, C. (2010). Corporal punishment and long-term behavior problems: The moderating role of positive parenting and psychological aggression. Psicothema, 22(4), 529-536. Retrieved from http://www.psicothema.com/ english/psicothema.asp?id=3762

Gershoff, E. T. (2002). Corporal punishment by parents and associated child behaviors and experiences: A meta-analytic and theoretical review. Psychological Bulletin, 128(4), 539-579. http://dx.doi.org/10.1037//0033-2909.128.4.539

Gershoff, E. T. (2010). More harm than good: A summary of scientific research on the intended and unintended effects of corporal punishment on children. Law and Contemporary Problems, 73, 31-56.

Gershoff, E. T. (2013). Spanking and child development: We know enough now to stop hitting our children. Child Development Perspectives, 7(3), $133-137$. http://dx.doi.org/10.1111/cdep.12038

Global Initiative to End All Corporal Punishment of Children. (2012). United Republic of Tanzania - Country report. , http://www.endcorporalpunishment.org/ pages/pdfs/states-reports/UR Tanzania.pdf.

Goodman, R., Ford, T., Simmons, H., Gatward, R., \& Meltzer, H. (2000). Using the Strengths and Difficulties Questionnaire (SDQ) to screen for child psychiatric disorders in a community sample. British Journal of Psychiatry, 177(6), 534-539. http://dx.doi.org/10.1192/bjp.177.6.534

Goodman, R., Meltzer, H., \& Bailey, V. (1998). The strengths and difficulties questionnaire: A pilot study on the validity of the self-report version. European Child \& Adolescent Psychiatry, 7(3), 125-130. http://dx.doi.org/10.1007/s007870050057

Hermenau, K., Hecker, T., Elbert, T., \& Ruf-Leuschner, M. (in press). Maltreatment and mental health in institutional care-comparing early- and late institutionalized children in Tanzania. Infant Mental Health Journal.

Hermenau, K., Hecker, T., Ruf, M., Schauer, E., Elbert, T., \& Schauer, M. (2011). Childhood adversity, mental ill-health and aggressive behavior in an African orphanage: Changes in response to trauma-focused therapy and the implementation of a new instructional system. Child and Adolescent Psychiatry and Mental Health, 5(1), 29. http://dx.doi.org/10.1186/1753-2000-5-29

Kashala, E., Elgen, I., Sommerfelt, K., \& Tylleskar, T. (2005). Teacher ratings of mental health among school children in Kinshasa, Democratic Republic of Congo. European Child E Adolescent Psychiatry, 14(4), 208-215. http://dx.doi.org/10.1007/s00787-005-0446-y

Lansford, J. E. (2010). The special problem of cultural differences in effects of corporal punishment. Law and Contemporary Problems, 73, 89-106.

Lansford, J. E., Malone, P. S., Dodge, K. A., \& Deater-Deckard, K. (2010). Children's perceptions of maternal hostility as a mediator of the link between discipline and children's adjustment in four countries. International Journal of Behavioral Development, 34(5), 452-461. http://dx.doi.org/10.1177/0165025409354933

Mulvaney, M. K., \& Mebert, C. J. (2007). Parental corporal punishment predicts behavior problems in early childhood. Journal of Family Psychology, 21, 389-397. http://dx.doi.org/10.1037/0893-3200.21.3.389

Raine, A., Dodge, K. A., Loeber, R., Gatzke-Kopp, L., Lynam, D., Reynolds, C., Stouthamer-Loeber, M., \& Liu, J. (2006). The reactive-proactive aggression questionnaire: Differential correlates of reactive and proactive aggression in adolescent boys. Aggressive Behavior, 32,159-171. http://dx.doi.org/10.1002/ab

Repetti, R. L., Taylor, S. E., \& Seeman, T. E. (2002). Risky families: Family social environments and the mental and physical health of offspring. Psychological Bulletin, 128(2), 330-366. http://dx.doi.org/10.1037/0033-2909.128.2.230

Savina, E., Coulacoglou, C., Sanyal, N., \& Zhang, J. (2011). The study of externalizing and internalizing behaviours in Greek, Russian, Indian, and Chinese children using the Fairy Tale Test. School Psychology International, 33(1), 39-53. http://dx.doi.org/10.1177/0143034311406821

Schilling, E., Aseltine, R., \& Gore, S. (2007). Adverse childhood experiences and mental health in young adults: A longitudinal survey. BMC Public Health, 7, 30. http://dx.doi.org/10.1186/1471-2458-7-30

Severance, L., Bui-Wrzosinska, L., Gelfand, M. J., Lyons, S., Nowak, A., Borkowski, W., Soomro, N., Soomro, N., Rafaeli, A., Efrat Treister, D., Lin, C.-C., \& Yamaguchi, S. (2013). The psychological structure of aggression across cultures. Journal of Organizational Behavior, 34, 835-865. http://dx.doi.org/10.1002/job.1873

Stevens, J. (2002). Applied multivariate statistics for the social sciences (4th ed.). Mahwah, NJ: Erlbaum.

Strassberg, Z., Dodge, K. A., Pettit, G. S., \& Bates, J. E. (1994). Spanking in the home and children's subsequent aggression toward kindergarten peers. Development and Psychopathology, 6(3), 445-461. http://dx.doi.org/10.1017/S0954579400006040

Straus, M. A. (2001). Beating the devil out of them: Physical punishment in American families (2nd ed.). New Brunswick, NJ: Transaction Publishers.

Straus, M. A. (2010). Prevalence, societal causes, and trends in corporal punishment by parents in world perspective. Law and Contemporary Problems, 31 , 1-30. http://scholarship.law.duke.edu/lcp/vol73/iss2/2

Straus, M. A., \& Kantor, G. K. (1994). Corporal punishment of adolescents by parents: A risk factor in the epidemiology of depression, suicide, alcohol abuse, child abuse, and wife beating. Adolescence, 29, 543-563. www.ncbi.nlm.nih.gov/pubmed/7832020

Tanzania Daily News. (2013). Public Schools to Continue Using Corporal Punishment. Daressalaam, Tanzania. http://allafrica.com/stories/ 201304090024.html

UNICEF. (2010). Child disciplinary practices at home: Evidence from a range of Low- and Middle-Income Countries, New York, USA. http://srsg.violence againstchildren.org/document/_830

UNICEF. (2011). Violence against children in Tanzania: Results from a National Survey 2009. Dar es Salaam, Tanzania. http://www.unicef.org/media/ files/VIOLENCE_AGAINST_CHILDREN_IN_TANZANIA_REPORT.pdf

Vittrup, B., \& Holden, G. W. (2010). Children's assessments of corporal punishment and other disciplinary practices: The role of age, race, SES, and exposure to spanking. Journal of Applied Developmental Psychology, 31(3), 211-220. http://dx.doi.org/10.1016/j.appdev.2009.11.003

Weaver, C. M., Borkowski, J. G., \& Thomas, L. (2008). Violence breeds violence: Childhood exposure and adolescent conduct problems. Journal of Community Psychology, 36(1), 96-112. http://dx.doi.org/10.1002/jcop.20219

Weiss, B., Dodge, K. A., Bates, J. E., \& Pettit, G. S. (1992). Some consequences of early harsh discipline: Child aggression and a maladaptive social information processing style. Child Development, 63(6), 1321-1335. http://dx.doi.org/10.2307/1131558 